\title{
Regulation of Extracellular Chromatin Release from Neutrophils
}

\author{
Indira Neeli Nishant Dwivedi Salar Khan Marko Radic \\ Department of Molecular Sciences, University of Tennessee Health Science Center, Memphis, Tenn., USA
}

\section{Key Words}

Neutrophils · Cytoskeleton · Chromatin · Histones ·

Deimination

\begin{abstract}
Neutrophils use intricate mechanisms for capturing and killing invading microorganisms. One mechanism entails the release of relaxed chromatin from the cell. Microbes are trapped by the extracellular chromatin and exposed to high local concentrations of bactericidal compounds. We examine the regulation of chromatin release by testing the contribution of microtubules and the actin cytoskeleton to the deployment of neutrophil extracellular traps (NETs). Incubation of human neutrophils with nocodazole, a tubulin polymerization inhibitor, or cytochalasin D, an inhibitor of actin filamentation, severely diminished the ability of neutrophils to respond to LPS by releasing chromatin from the cells. In addition, pretreatment of neutrophils with $\mathrm{M} 1 / 70$, a monoclonal antibody to the Mac-1 integrin adhesion receptor, drastically reduced the deployment of chromatin into NETs. Analysis of histone deimination, the conversion of arginine to citrulline in 3 of the 4 core histones by peptidylarginine deiminase 4 , revealed that the treatments inhibiting NET formation also reduced histone deimination. Our data indicate that NET formation requires functional tubulin and actin filaments and responds to engagement of Mac-1 integrins. Because histone deimination coincides with the release of NETs, we propose that these events represent overlapping mechanisms of neutrophil responses to infections.

Copyright $\odot 2009$ S. Karger AG, Basel
\end{abstract}

\section{Introduction}

In infections, neutrophils represent the host's most numerous and effective front-line defenders $[1,2]$. When microbes breach an external barrier of the body, resident tissue macrophages emit distress signals that activate endothelia and recruit large numbers of neutrophils to the site of infection [3]. Neutrophils leave the circulation by adhering to blood vessel walls, passing through the endothelium, and migrating along gradients of distress signals and microbial breakdown products [4].

Neutrophils arriving at the site of an infection engage a remarkable mechanism. Within minutes, they relax chromatin, expand the nucleus and rupture the nuclear envelope [5]. Subsequently, the plasma membrane opens to release chromatin from the cell [5-7]. The released chromatin is composed of extended chromatin fibers that intersect and bundle with each other [6], forming a meshwork that immobilizes extracellular microorganisms $[8$, 9]. For that reason, the chromatin network has been called neutrophil extracellular traps (NETs).

Because the dissolution of the nuclear envelope coincides with the release of neutrophil granule contents into the cytoplasm, the unfolding chromatin associates with a plethora of bactericidal compounds [8]. Following the release of NETs, microbes are immobilized and exposed to substances that assist in pathogen destruction $[10,11]$. Recent studies have revealed that mast cells may also release chromatin [12]. Conversely, pathogens express nu-

\section{KARGER \\ Fax +4161306 1234 \\ E-Mail karger@karger.ch}

www.karger.com (c) 2009 S. Karger AG, Basel

1662-811X/09/0013-0194\$26.00/0

Accessible online at:

www.karger.com/jin
Dr. Marko Radic

Department of Molecular Sciences

University of Tennessee Health Science Center

858 Madison Avenue, Room 211, Memphis, TN 38163 (USA)

Tel. +1 901448 8219, Fax +1 901448 8462, E-Mail mradic@utmem.edu 
cleic acid-degrading enzymes as part of their armamentarium [13-15].

The release of neutrophil chromatin represents a unique form of cell death that is quite distinct from the more widely studied forms of cell death, namely apoptosis and necrosis [5]. The release of NETs requires the production of reactive oxygen species by NADPH oxidase, and neutrophils lacking this enzyme are incapable of releasing nuclear chromatin [5]. However, additional aspects of NET release remain unexplored.

Preparations for the deployment of chromatin in NETs may include specific, global modifications of histones that arrest gene activity and relax higher-order structure. To unwind chromatin, interactions between histones and DNA may have to be weakened. Deimination of histones by peptidylarginine deiminase 4 [16] is one posttranslational modification that would alter interactions with DNA because it replaces positively charged arginines with uncharged citrullines [17]. We hypothesized that histone deimination is an important mark of large-scale transitions in chromatin structure and that it plays an important role in the structure and function of NETs. To test this idea, we carried out studies on the requirements for histone deimination and NET formation.

Previously, we observed parallels between the release of NETs and histone deimination [18]. Deimination is induced under conditions that induce NETs and deiminated histones are incorporated into NETs [18]. Here, we asked whether disruption of actin or tubulin polymers, or inhibition of signaling through adhesion receptors, perturb the regulation of histone deimination and NET release.

\section{Methods}

\section{Antibodies and Supplies}

Anti-citrullinated histone $\mathrm{H} 3$ rabbit antibodies (Ab 5103) were obtained from AbCam (Cambridge, Mass., USA) and antitotal-histone $\mathrm{H} 3$ rabbit antibodies (07-690) from Upstate Biotechnology (Lake Placid, N.Y., USA). LPS, zymosan, apocynin and horseradish peroxidase (HRP)-conjugated secondary antibodies to rabbit or mouse Ig were purchased from Sigma (St. Louis, Mo., USA). Goat anti-rabbit AF 648, annexinV AF488 and Sytox Orange were obtained from Invitrogen (Carlsbad, Calif., USA). $\mathrm{H}_{2} \mathrm{O}_{2}$ was obtained from Fisher Scientific (Fairlawn, N.J., USA). $\mathrm{SecinH} 3$ was received from Merck KGaA (Darmstadt, Germany). Recombinant human TNF was supplied by Biosource (Carlsbad, Calif., USA). Lipoteichoic acid (LTA) was a kind gift from Dr. David Hasty (VA, Memphis, Tenn., USA).

Neutrophil Isolation and Treatments

Neutrophils were isolated from blood of healthy donors purchased from Lifeblood Biological Services (Memphis, Tenn.,
USA) and used in accord with protocols approved by the University of Tennessee institutional review board. Neutrophils were purified following modified methods of Wang et al. [19] and Sergeant et al. [20]. Briefly, neutrophils were enriched at room temperature in the supernatant from a isolymph sedimentation and recovered from an Isolymph density gradient (Gallard-Schlesinger, Plainview, N.Y., USA) under endotoxin-free conditions.

Polypropylene tubes containing neutrophils were transferred to ice, the remaining erythrocytes were lysed in ice-cold hypotonic $(0.2 \%) \mathrm{NaCl}$ for $30 \mathrm{~s}$, and the solution was rendered physiological saline by addition of hypertonic (1.6\%) NaCl. At this point, neutrophil viability was typically $>98 \%$, as assessed by Trypan Blue dye exclusion.

Neutrophils were suspended at a density of $2 \times 10^{6} / \mathrm{ml}$ in PBS supplemented with $0.1 \%$ glucose and $0.5 \%$ heat-inactivated human serum, but without $\mathrm{Ca}^{++}$or $\mathrm{Mg}^{++}$. Neutrophils were stimulated with increasing concentrations of TNF, LPS, zymosan, LTA or $\mathrm{H}_{2} \mathrm{O}_{2}$ in the presence of $2 \mathrm{mM}$ calcium at $37^{\circ} \mathrm{C}$ for $2 \mathrm{~h}$. Following the incubations, cells were washed with cold PBS and cell lysates were prepared in SDS-lysis buffer (2\% SDS in $62.5 \mathrm{mM}$ Tris, pH 6.8, supplemented with 5\% 2-mercaptoethanol and $10 \%$ glycerol). Lysates were sonicated and protein concentrations were measured by using a Nanodrop 1000 spectrophotometer (Thermo Scientific, Wilmington, Del., USA).

\section{Western Blotting}

Cell lysates were analyzed as previously described [18]. Briefly, samples were separated on 12\% SDS-PAGE and proteins were transferred to nitrocellulose membranes. Membranes were blocked for $1 \mathrm{~h}$ at room temperature with 5\% BSA in TBST (25 $\mathrm{mM}$ Tris $\mathrm{pH} 7.2,150 \mathrm{mM} \mathrm{NaCl}$ and $0.1 \%$ Tween) and rinsed before incubation at $4^{\circ} \mathrm{C}$ with primary antibodies diluted in TBST. Subsequently, membranes were washed and incubated with goatanti-rabbit secondary antibody conjugated to HRP for $1 \mathrm{~h}$ at room temperature, washed 3 times with TBST and twice with TBS alone. The HRP activity was detected by using chemiluminescence reagent plus (PerkinElmer Life Sciences Inc., Boston, Mass., USA). Relative intensities of immunoreactive bands were quantitated using image analysis software (Adobe, San Jose, Calif., USA). Experiments were performed at least three separate times with consistent results.

\section{Confocal Microscopy}

Neutrophils were allowed to settle for 30 min onto glass coverslips that were precoated with $0.001 \%$ poly-L-lysine and placed in wells of 6 -well tissue culture plates at $37^{\circ} \mathrm{C}$ in $5 \% \mathrm{CO}_{2}$. The cells were treated with LPS or alternative treatments and incubated for $1 \mathrm{~h}$ at $37^{\circ} \mathrm{C}$. The coverslips were washed inside the wells with icecold HBSS, the cells were fixed with 6\% PFA in HBSS for 15 min at room temperature and blocked overnight with blocking solution (HBSS with 10\% FBS, 1\% BSA, 0.05\% Tween 20 and $2 \mathrm{mM}$ EDTA) at $4^{\circ} \mathrm{C}$. The coverslips were washed with wash buffer (HBSS with 3\% FBS), incubated with rabbit anti-citrullinated histone $\mathrm{H} 3$ antibodies (diluted 1:100 in wash buffer) for $30 \mathrm{~min}$ at $4^{\circ} \mathrm{C}$, washed again, and incubated with goat-anti-rabbit IgG coupled with AF 647, Sytox Orange, and annexin V coupled to AF 488 for $30 \mathrm{~min}$ at $4^{\circ} \mathrm{C}$. Annexin $\mathrm{V}$ is a useful marker for the plasma membrane of cells treated as above with paraformaldehyde and low concentrations of Tween 20 [21,22]. Following addition of fluorochromes, coverslips were washed, mounted on slides in wash 
buffer containing $50 \%$ glycerol, and analyzed by confocal microscopy, as previously described [23]. Percentages of cells releasing NETs were determined by counting between 300 and 400 cells for each of the treatments and averaging the results. Experiments were performed at least 3 separate times with consistent results.

\section{Results}

\section{Inflammatory Stimuli Induce Histone Deimination and NET Formation}

Neutrophils are exquisitely sensitive to signals of an ongoing infection, among them cytokines and microbial breakdown products that activate neutrophils [1]. As examples of these substances, we used TNF, the quintessential proinflammatory cytokine, LPS and LTA, components of the Gram-negative and Gram-positive cell walls, respectively, and zymosan, the carbohydrate cell wall of fungi, to stimulate neutrophils in vitro. We also used hydrogen peroxide, a substance produced by the respiratory burst in neutrophils, and known to be essential for production of NETs [5]. Each of these stimuli induced robust histone deimination (fig. 1a) that was well above the background level of deimination observed in buffer alone. Higher concentrations of stimuli induced more deimination. The amount of total protein in the lysates was carefully adjusted prior to electrophoresis, and equal loading was confirmed by measuring total $\mathrm{H} 3$ histone (fig. 1a).

In parallel experiments, we asked whether neutrophils respond to inflammatory stimuli by production and release of NETs. Previous studies had demonstrated that treatments employed in figure la induce the formation of NETs $[6,10,18]$. Our previous data indicated that fewer than half of NETs react with antibodies to deiminated histone $\mathrm{H} 3$ [18]. We used this observation here to explore the regulation and timing of histone deimination.

In contrast to unstimulated neutrophils that have rounded cellular outlines and lobed nuclei (fig. 1b), neutrophils stimulated with hydrogen peroxide released NETs as early as $1 \mathrm{~h}$ after addition of the stimulus (fig. 1c). As highlighted in figure 1c, one of the neutrophils (indicated by the violet arrow) cast a NET that reacted intensely with the antideiminated histone $\mathrm{H} 3$ antibody (red) and the Sytox orange stain for DNA (blue). The overlap of the 2 fluorescence signals results in an intense violet color. In contrast, a second neutrophil, immediately adjacent to the first, cast a NET that failed to react with the antibody (fig. 1c, blue arrow). This result suggested that histone deimination is accomplished prior to the rupture of the plasma membrane and ceases upon NET release.
Disruption of the Cytoskeleton Inhibits Histone

\section{Deimination and NET Release}

Large-scale transitions in cell morphology almost always involve contributions of the cytoskeleton. In neutrophils, cell attachment, migration and phagocytosis are among the key processes requiring the functions of the actin cytoskeleton [24]. Microtubules carry out important functions in the transport of cell organelles, including lysosomes and granules, and organelle fusion with membranes [25]. Clearly, one might predict that the release of NETs requires the participation of both actin and tubulin networks, although it is not obvious at which step the cytoskeleton provides a critical contribution. Similarly, histone deimination may require signals involving the cytoskeleton, although this has not previously been examined.

To test the involvement of microtubules and actin filaments in histone deimination and NET formation, we incubated neutrophils in nocodazole, a drug that interferes with tubulin polymerization into microtubules, or cytochalasin $\mathrm{D}$, a drug that disrupts the polymerization of actin filaments. Pretreatment with nocodazole prior to LPS addition to neutrophils inhibited $53 \%$ of histone deimination relative to LPS alone (fig. 2a), and cytochalasin D inhibited $47 \%$ of the deimination observed with LPS alone (fig. 2a). Apocynin, a drug that inhibits NADPH oxidase and thus blocks production of reactive oxygen [26], was slightly more effective in blocking deimination (64\% reduction relative to LPS alone). Because cytochalasin D and nocodazole substantially reduced histone deimination, we asked whether NET release would likewise be affected.

The effects of cytochalasin D and of nocodazole on NET production and release were striking. Just over $30 \%$ of cells treated with LPS in the absence of cytoskeletal inhibitors released NETs (fig. 2b), while others lost the constrained lobed structure of the nucleus and were thus poised for NET release. Nearly one third of the cells releasing NETs ( $32 \%$ in the experiment shown) reacted positive for deiminated histone $\mathrm{H} 3$ (fig. 2b).

In contrast, cells that were pretreated with nocodazole prior to addition of LPS had a largely normal polymorphonuclear granulocyte appearance, in that nearly two thirds of the cell population did not appreciably differ from controls (compare fig. $2 \mathrm{c}$ to fig. 1b). Remaining cells had progressed to the disintegration of the nucleus, yet overall only $5 \%$ of cells had released NETs (fig. 2e). Importantly, less than $3 \%$ of all cells showed pyknotic nuclei, indicating that few cells entered apoptosis under the conditions used in our experiments. Nocodazole treatment 


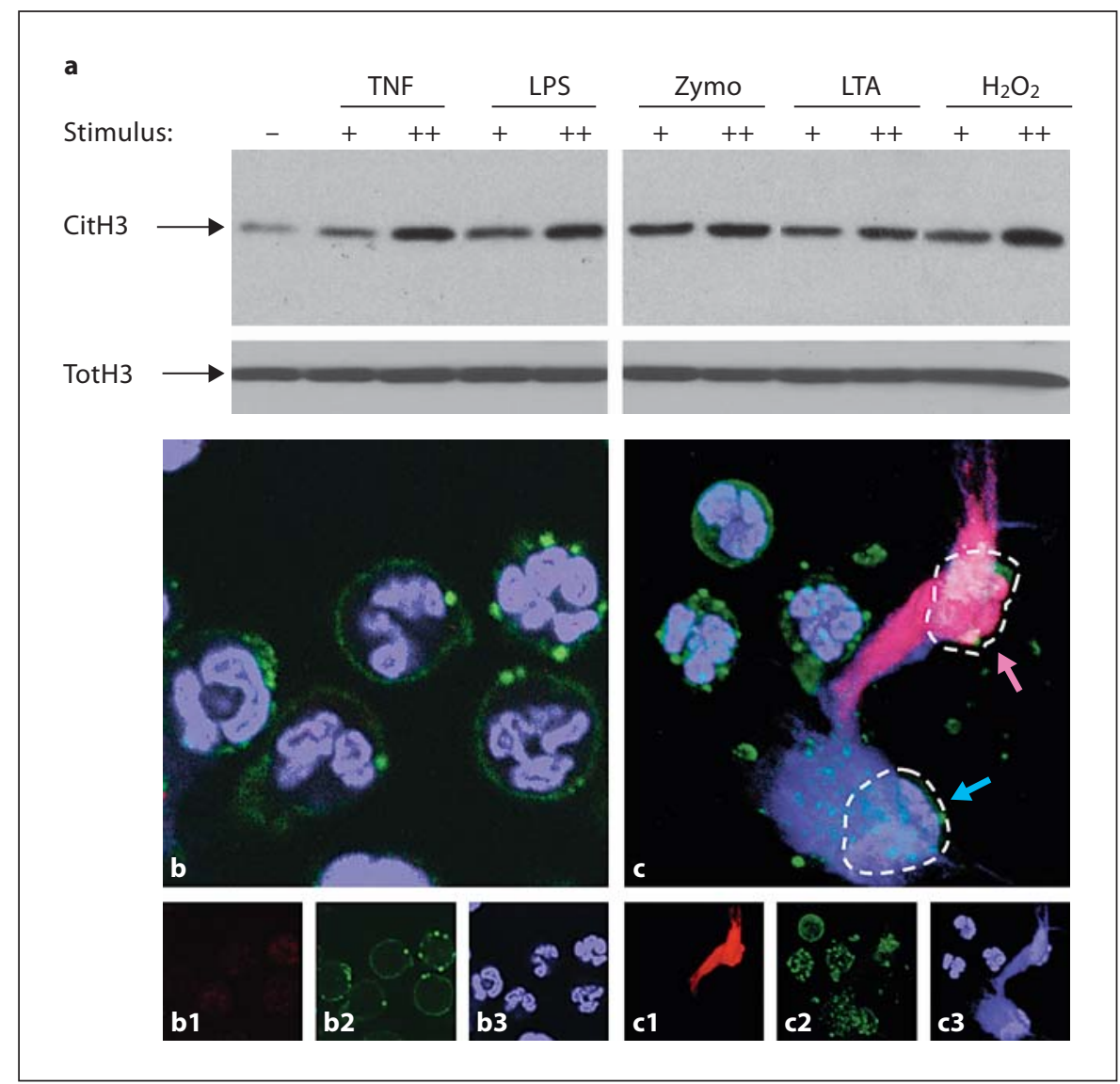

Fig. 1. Diverse inflammatory stimuli induce histone deimination and NET release. a Histone deimination was determined by Western blot (CitH3). Neutrophils were incubated in buffer alone (-) or in the presence of TNF $(+=2 \mathrm{ng} / \mathrm{ml} ;++=8 \mathrm{ng} / \mathrm{ml})$, LPS $(+=10$ $\mathrm{ng} / \mathrm{ml} ;++=100 \mathrm{ng} / \mathrm{ml})$, zymosan $(Z y m o ;+=1 \mu \mathrm{g} / \mathrm{ml} ;++=10$ $\mu \mathrm{g} / \mathrm{ml})$, LTA $(+=1 \mu \mathrm{g} / \mathrm{ml} ;++=6 \mu \mathrm{g} / \mathrm{ml})$ or hydrogen peroxide $\left(\mathrm{H}_{2} \mathrm{O}_{2} ;+=10 \mu \mathrm{M} ;++=100 \mu \mathrm{M}\right)$. Each stimulus enhanced histone deimination, with higher concentrations of stimuli inducing greater deimination. The samples that were analyzed contained comparable amounts of total histone $\mathrm{H} 3$ (TotH3). b Neutrophils retain normal morphology with typical multilobed nuclei following incubation in buffer alone. DNA was visualized with Sytox orange (blue) and the plasma membrane with annexin $\mathrm{V}$ (green). c Neutrophils incubated in $100 \mu \mathrm{M} \mathrm{H}_{2} \mathrm{O}_{2}$ display NETs. The NET released from the cell at top right (violet arrow) also reacts with antibody to deiminated histone $\mathrm{H} 3$ (red), whereas the NET from the cell on the bottom right (blue arrow) does not. Broken lines indicate the footprints of the two cells. In addition to the composite color images, corresponding separate color images are shown for $\mathbf{b}$ and c. 1 = Antibody binding; 2 = annexin V; 3 = DNA staining. also greatly reduced reactivity with the antideiminated histone H3 antibody. Similarly, only $9 \%$ of cells treated with cytochalasin D progressed to NET release, and most retained a naïve neutrophil morphology (fig. $2 \mathrm{~d}$ ).

Remarkably, cells that were treated with cytochalasin D prior to incubation with LPS displayed a unique characteristic. In these cells, the nuclear envelope had disintegrated and allowed chromatin to mix with the cytoplasmic contents, yet the plasma membrane remained an effective barrier to the release of NETs (fig. 2d). Neutrophils whose NET release was restrained by cytochalasin D treatment were able to reach twice the diameter of un- stimulated cells (fig. $2 \mathrm{~d}$, insert). It is possible that actin filaments play a role in allowing the rupture of the plasma membrane and the deployment of NETs. In addition, the actin network may function to push the chromatin through a breach in the plasma membrane. Further studies will be required to relate the disruption of the actin cytoskeleton to the increase in cell diameter.

\section{Cell Attachment and Integrin Signaling Assist in Histone Deimination and NET Release}

Because the majority of neutrophils treated with cytochalasin D did not show evidence of responding to LPS 


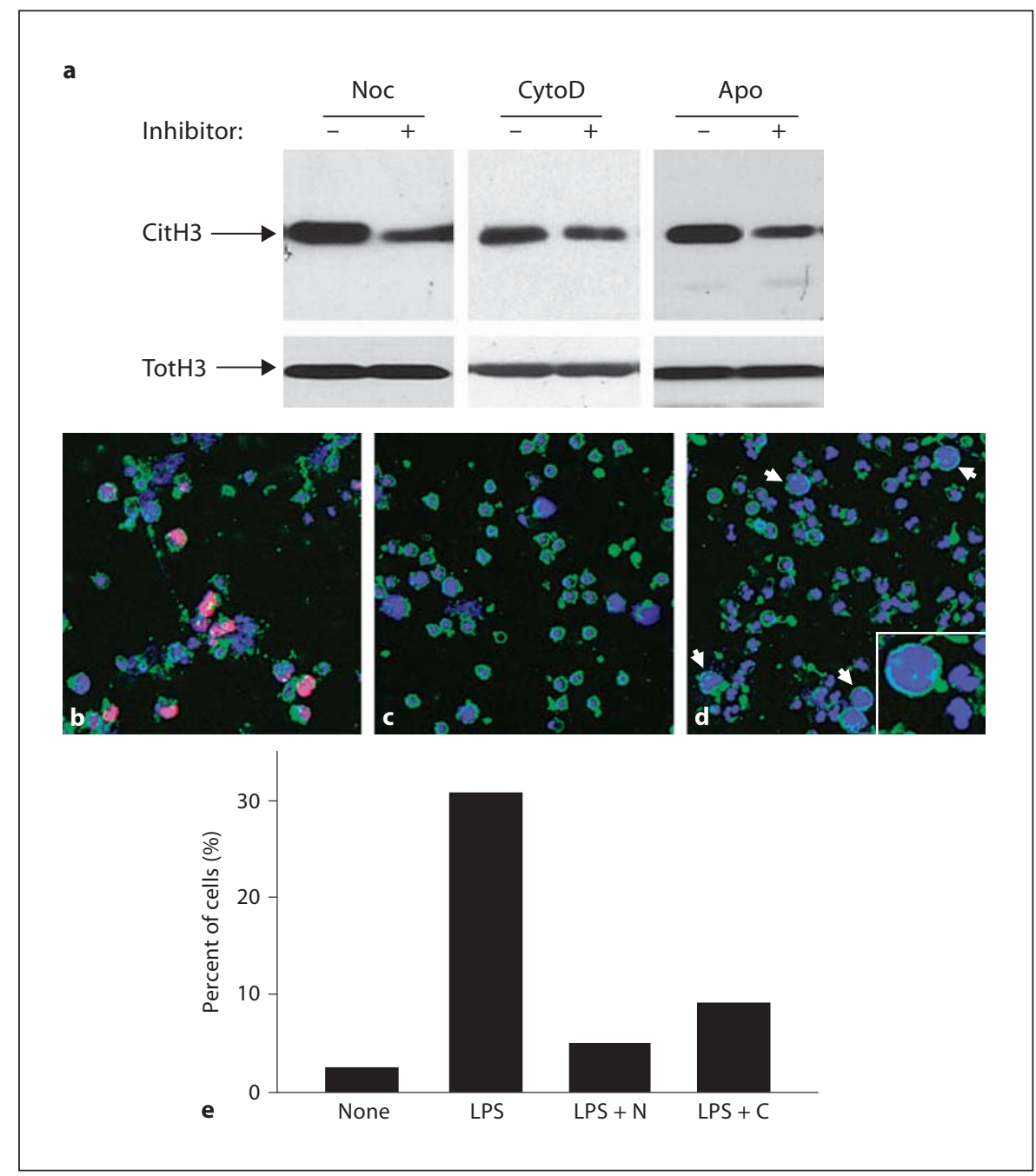

Fig. 2. Drugs that depolymerize microtubules or actin filaments inhibit histone deimination and NET release. a Deiminated histone $\mathrm{H} 3$ (CitH3) and total H3 (TotH3) were determined by Western blot following incubation of neutrophils in $100 \mathrm{ng} / \mathrm{ml} \mathrm{LPS}$. Neutrophils were preincubated in the absence $(-)$ or presence $(+)$ of $10 \mu \mathrm{M}$ nocodazole (Noc), $10 \mu \mathrm{M}$ cytochalasin D (CytoD) or 100 $\mu \mathrm{M}$ apocynin (Apo). b Microscopy of cells incubated in $100 \mathrm{ng} / \mathrm{ml}$ LPS shows nuclear dissolution and NET release. Antideiminated histone $\mathrm{H} 3$ binding is visualized in red. Other colors are as in fig- ure 1. c Cells preincubated in nocodazole show a greatly reduced morphological response to LPS. $\mathbf{d}$ Pre-incubation in cytochalasin $D$ reduced NET release in response to LPS and caused accumulation of cells with increased diameter whose interior was filled with homogeneously dispersed chromatin (arrows and inset). e Multiple views of the cell populations shown in $\mathbf{b}$-d versus untreated cells were recorded, analyzed for NET release, and the results were plotted. treatment, we wondered whether the cytoskeleton is required to sense and transmit external signals that culminate with NET release. Leukocyte integrins are cell surface receptors whose cytoplasmic domains engage the actin cytoskeleton [27].

To test whether integrin binding contributes toward histone deimination and NET release, we inhibited Mac1 integrin, the complement receptor composed of the $\alpha_{M} /$ $\beta_{2}$ integrin subunits [28], with $\mathrm{M} 1 / 70$, an IgG antibody that inhibits Mac-1 binding [29]. Mac-1 binds a variety of ligands, including poly-L-lysine that was used to coat the coverslips for this experiment [30]. The antibody was administered 30 min before addition of LPS. We observed a $51 \%$ decrease in histone deimination compared to deimination observed in the absence of M1/70 or the presence of a control IgG (fig. 3a and c). 


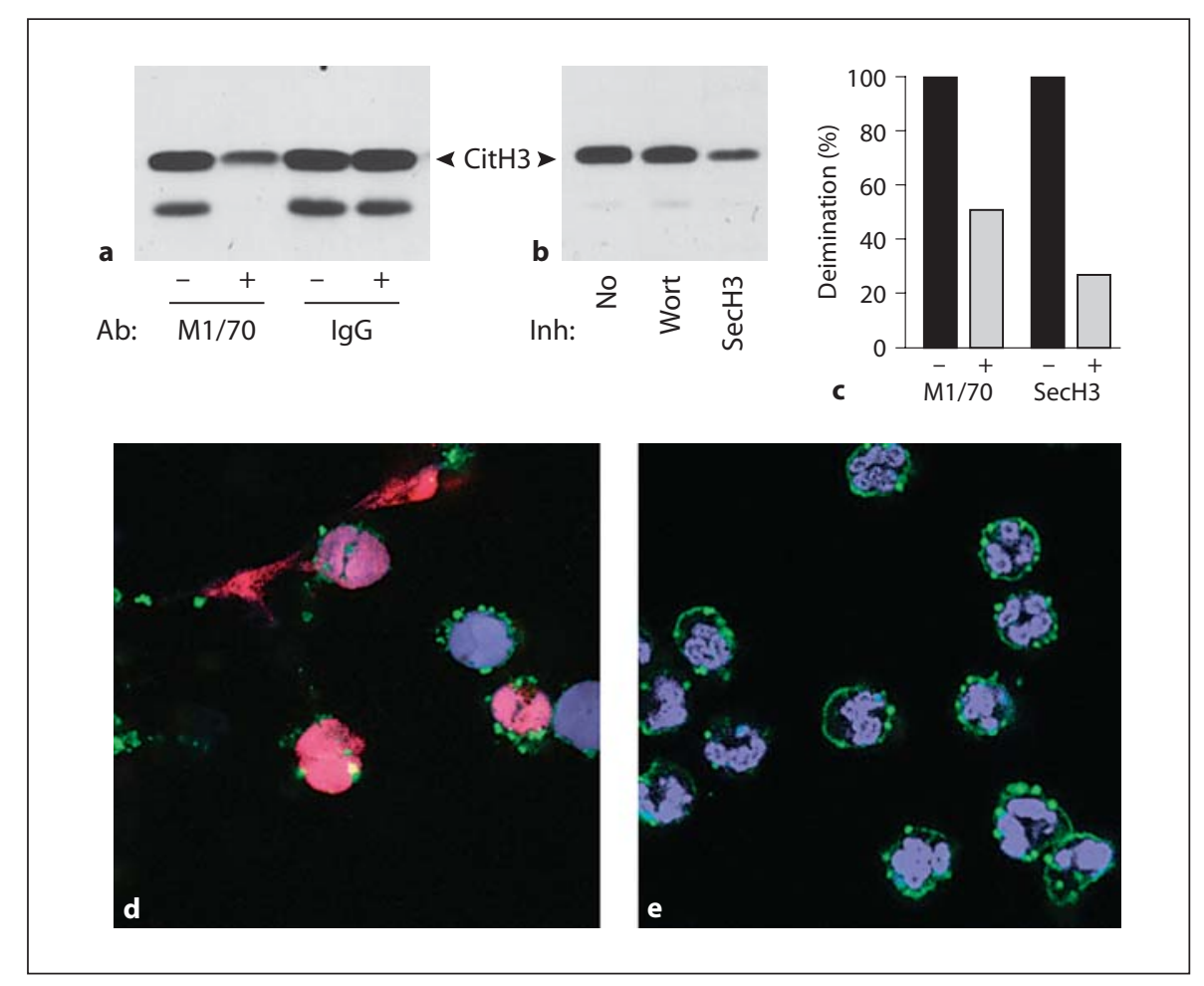

Fig. 3. Pretreatment of neutrophils with anti-Mac-1 antibody or secinH3 reduces response to LPS. a Neutrophils were incubated with $10 \mu \mathrm{g} / \mathrm{ml}$ of M1/70, an anti-Mac-1 IgG, or an isotype-matched control IgG, for $30 \mathrm{~min}$ prior to addition of $100 \mathrm{ng} / \mathrm{ml} \mathrm{LPS}$. Deiminated histone $\mathrm{H} 3$ was detected by Western blot (CitH3), indicating that M1/70 reduced deimination. Neutrophil lysates also exhibited a faster migrating immunoreactive band [18]. b Neutrophils incubated without inhibitor (No), with $50 \mu \mathrm{M}$ Wortmannin
(Wort) or $10 \mu \mathrm{M}$ secinH3 (SecH3) prior to addition of $100 \mathrm{ng} / \mathrm{ml}$ LPS. SecinH3 inhibited histone deimination. c Deimination was measured by densitometry of immunoreactive bands and displayed as percent of deimination observed in the absence or presence of M1/70 or SecinH3. d Cells incubated with $100 \mathrm{ng} / \mathrm{ml} \mathrm{LPS}$ show NETs and histone deimination. Colors represent fluorescence acquired as in figure 1. e Cells treated with M1/70 show a greatly reduced morphological response to LPS than cells in $\mathbf{d}$.
To test one likely pathway linking Mac-1 to the actin cytoskeleton, we inhibited cytohesin-1, the guanine nucleotide exchange factor that associates with the $\beta_{2}$ integrin subunit and, when phosphorylated, tightly binds to the actin cytoskeleton [31]. Recently, secinH3, a specific antagonist of cytohesin-1 function was developed [32], and we tested its effect on the induction of histone deimination by LPS (fig. 3b). SecinH3 inhibited $73 \%$ of the LPS-induced histone deimination (fig. $3 \mathrm{~b}$ and c), whereas Wortmannin, the phosphoinositide-3-kinase inhibitor [33], had a negligible effect (fig. 3b). We interpret these results as evidence that integrin engagement and signaling mediated by cytohesin-1 facilitate LPS-induced histone deimination.

The effect of Mac-1 inhibition by M1/70 on NET release was dramatic. While cells responded to LPS treatment by rounding their multilobed nuclei, becoming re- active with the anti-deiminated histone antibody, and ultimately releasing NETs (fig. 3d), cells preincubated with M1/70 showed few of the dramatic responses to LPS (fig. 3e). Therefore, our data suggest that integrin Mac-1 engagement and signaling through the cytohesin-1 pathway are central to the inflammatory response in neutrophils in that they contribute to the regulation of histone deimination and NET release.

\section{Discussion}

Our study represents the first exploration of the role of the cytoskeleton in NET release and histone deimination. Our data identify a major contribution of both microtubules and actin filaments in LPS-induced histone deimination, nuclear dissolution and NET release. Our 
observations add to the previously identified conditions [18] that act in parallel to induce (or inhibit) histone deimination and NET release. Thus, we remain unable to experimentally uncouple these events and must conclude that histone deimination and NET release are linked by a common mechanism or that they serve a common function in the response to infection.

Despite the precise overlap in the stimuli that induce histone deimination and NET release, our microscopic analysis indicates that antibodies to the deiminated histone $\mathrm{H} 3$ only bind to a subset of NETs. One interpretation of this result is that production of NETs does not require histone deimination. We suspect that this interpretation is incorrect, but currently we cannot disprove it. We suggest that deimination of other core histones $(\mathrm{H} 2 \mathrm{~A}$ or $\mathrm{H} 4)$ can suppress deimination of $\mathrm{H} 3$, or that additional, superimposed $\mathrm{H} 3$ modifications block the binding of antibodies to the deiminated amino terminus of H3. Unfortunately, there are no specific antibodies for the other deiminated histones, and therefore resolution of this question will have to await the development of additional monospecific antibodies.

Nevertheless, our results suggest a pathway for the regulation of histone deimination and NET release. The proposed pathway integrates signals from inflammatory stimuli (acting through innate receptors such as Toll-like receptors) with the engagement of Mac-1 integrin by ligands outside the cell. Possible ligands for Mac-1 could be complement-coated pathogens [28] or aggregated platelets, as might occur in sepsis [34]. The integration of 2 signals, as proposed here, is common to many adaptive and innate immune responses [35]. Neutrophils respond to inputs from Mac-1 integrins and Toll-like receptors, in effect combining environmental cues with inflammatory stimuli, to deiminate histones and release NETs. Our result suggests that NET release is contingent on specific interactions with the cell surface and that NETs may be cast toward the source of the stimulus.

How can the cytoskeleton contribute to histone deimination and NET release? Because we can detect histone deimination within $15 \mathrm{~min}$ after neutrophil stimulation by LPS and deiminated histones localize to distinct foci in neutrophil nuclei [18], the cytoskeleton may serve to transmit signals from the cell surface to the nucleus. As the nuclear envelope disintegrates and chromatin mixes with the cytoplasm, reactivity of deiminated histones becomes more intense [18]. Granule membranes disintegrate at that particular time, as reported by Fuchs et al. [5]. If peptidylarginine deiminase 4 is indeed associated with tertiary granules [36], the mixing of chromatin and granule contents may promote histone deimination.

Our observations further suggest that the cytoskeleton regulates the release of chromatin NETs. Microtubules determine the direction of exocytosis in neutrophils [25], and here we observed that microtubule depolymerization by nocodazole prevented nuclear breakdown and NET release (fig. 2c). Cytochalasin D treatment led to similar inhibition, indicating that the actin cytoskeleton also participates in regulating chromatin release (fig. $2 \mathrm{~d}$ ). The cytoskeleton positions the nucleus relative to the plasma membrane [37]. This may be the specific contribution of the actin cytoskeleton to the breakdown of the nuclear and plasma membranes, thus facilitating the release of NETs. The coordinated interplay between the microtubule and actin filaments may be required in order to ensure the proper temporal and spatial control of NET deployment. Our data suggest that Mac-1 occupies a central position at the point of initiation of these cytoskeletal rearrangements.

Mac-1 integrins also play important roles in neutrophil recognition of prey to be captured by phagocytosis [28]. Together with the present findings, those data suggest that the same receptors determine whether a neutrophil will undergo phagocytosis or NET release. Indeed, studies with Candida albicans show neutrophils that are engaged in NET release near others that are attempting phagocytosis [10]. Thus, engulfment of microbes by phagocytosis may be an alternative to the extracellular trapping of microbes. Whether a neutrophil engages in one or the other defense mechanism may depend on the degree of functional specialization of the neutrophil or the nature of the microbe. It is tempting to speculate that guanine exchange factors such as cytohesin-1 [31] may be ideally positioned to sense the topology of the prey and direct appropriate neutrophil responses. Our data showing that the cytohesin-1 pathway regulates histone deimination suggest that neutrophils possess mechanisms to select among alternative responses to infection.

\section{Acknowledgements}

The authors thank Dr. David Hasty for the gift of LTA and Mr. Tim Higgins, senior illustrator, for expert assistance in the preparation of figures. The work presented was supported by a research grant from the Lupus Research Institute. 


\section{References}

1 Nathan C: Neutrophils and immunity: challenges and opportunities. Nat Rev Immunol 2006;6:173-182.

$\checkmark 2$ Medzhitov R: Origin and physiological roles of inflammation. Nature 2008;454:428435.

3 Ley K, Laudanna C, Cybulsky MI, Nourshargh S: Getting to the site of inflammation: the leukocyte adhesion cascade updated. Nat Rev Immunol 2007;7:678-689.

4 Phillipson M, Heit B, Colarusso P, Liu L, Ballantyne CM, Kubes P: Intraluminal crawling of neutrophils to emigration sites: a molecularly distinct process from adhesion in the recruitment cascade. J Exp Med 2006;203: 2569-2575.

-5 Fuchs TA, Abed U, Goosmann C, Hurwitz R, Schulze I, Wahn V, Weinrauch Y, Brinkmann V, Zychlinsky A: Novel cell death program leads to neutrophil extracellular traps. J Cell Biol 2007;176:231-241.

-6 Brinkmann V, Reichard U, Goosmann C, Fauler B, Uhlemann Y, Weiss DS, Weinrauch Y, Zychlinsky A: Neutrophil extracellular traps kill bacteria. Science 2004;303:15321535.

7 Martinelli S, Urosevic M, Daryadel A, Oberholzer PA, Baumann C, Fey MF, Dummer R, Simon HU, Yousefi S: Induction of genes mediating interferon-dependent extracellular trap formation during neutrophil differentiation. J Biol Chem 2004;279:44123-44132.

8 Brinkmann V, Zychlinsky A: Beneficial suicide: why neutrophils die to make NETs. Nat Rev Microbiol 2007;5:577-582.

9 Wartha F, Henriques-Normark B: ETosis: a novel cell death pathway. Sci Signal 2008;1: pe25.

10 Urban CF, Reichard U, Brinkmann V, Zychlinsky A: Neutrophil extracellular traps capture and kill Candida albicans yeast and hyphal forms. Cell Microbiol 2006;8:668-676.

11 Wartha F, Beiter K, Normark S, HenriquesNormark B: Neutrophil extracellular traps: casting the NET over pathogenesis. Curr Opin Microbiol 2007;10:52-56.

- 12 von Kockritz-Blickwede M, Goldmann O, Thulin P, Heinemann K, Norrby-Teglund A, Rohde M, Medina E: Phagocytosis-independent antimicrobial activity of mast cells by means of extracellular trap formation. Blood 2008;111:3070-3080.

13 Sumby P, Barbian KD, Gardner DJ, Whitney AR, Welty DM, Long RD, Bailey JR, Parnell MJ, Hoe NP, Adams GG, Deleo FR, Musser JM: Extracellular deoxyribonuclease made by group A Streptococcus assists pathogenesis by enhancing evasion of the innate immune response. Proc Natl Acad Sci USA 2005;102:1679-1684
14 Beiter K, Wartha F, Albiger B, Normark S, Zychlinsky A, Henriques-Normark B: An endonuclease allows Streptococcus pneumoniae to escape from neutrophil extracellular traps. Curr Biol 2006;16:401-407.

15 Buchanan JT, Simpson AJ, Aziz RK, Liu GY, Kristian SA, Kotb M, Feramisco J, Nizet V: DNase expression allows the pathogen group A Streptococcus to escape killing in neutrophil extracellular traps. Curr Biol 2006;16: 396-400.

16 Nakashima K, Hagiwara T, Ishigami A, Nagata $\mathrm{S}$, Asaga $\mathrm{H}$, Kuramoto $\mathrm{M}$, Senshu T, Yamada M: Molecular characterization of peptidylarginine deiminase in HL-60 cells induced by retinoic acid and 1 1 ,25-dihydroxyvitamin D(3). J Biol Chem 1999;274: 27786-27792.

17 Hagiwara T, Nakashima K, Hirano H, Senshu T, Yamada M: Deimination of arginine residues in nucleophosmin/B23 and histones in HL-60 granulocytes. Biochem Biophys Res Commun 2002;290:979-983.

18 Neeli I, Khan SN, Radic M: Histone deimination as a response to inflammatory stimuli in neutrophils. J Immunol 2008;180:18951902

19 Wang D, Pabst KM, Aida Y, Pabst MJ: Lipopolysaccharide-inactivating activity of neutrophils is due to lactoferrin. J Leukoc Biol 1995; $57: 865-874$

20 Sergeant S, Waite KA, Heravi J, McPhail LC: Phosphatidic acid regulates tyrosine phosphorylating activity in human neutrophils: enhancement of Fgr activity. J Biol Chem 2001;276:4737-4746.

21 Cocca BA, Cline AM, Radic MZ: Blebs and apoptotic bodies are B cell autoantigens. J Immunol 2002;169:159-166.

22 Neeli I, Richardson MM, Khan SN, Nicolo D, Monestier M, Radic MZ: Divergent members of a single autoreactive $B$ cell clone retain specificity for apoptotic blebs. Mol Immunol 2007;44:1914-1921.

23 Radic M, Marion T, Monestier M: Nucleosomes are exposed at the cell surface in apoptosis. J Immunol 2004;172:6692-6700.

24 Yan M, Di Ciano-Oliveira C, Grinstein S, Trimble WS: Coronin function is required for chemotaxis and phagocytosis in human neutrophils. J Immunol 2007;178:57695778 .

25 Tapper H, Furuya W, Grinstein S: Localized exocytosis of primary (lysosomal) granules during phagocytosis: role of $\mathrm{Ca}^{2+}$-dependent tyrosine phosphorylation and microtubules. J Immunol 2002;168:5287-5296.
26 Ximenes VF, Kanegae MP, Rissato SR, Galhiane MS: The oxidation of apocynin catalyzed by myeloperoxidase: proposal for NADPH oxidase inhibition. Arch Biochem Biophys 2007;457:134-141.

27 Jones SL, Knaus UG, Bokoch GM, Brown EJ: Two signaling mechanisms for activation of $\alpha \mathrm{M} \beta 2$ avidity in polymorphonuclear neutrophils. J Biol Chem 1998;273:1055610566.

28 Ross GD: Regulation of the adhesion versus cytotoxic functions of the Mac-1/CR3/ $\alpha \mathrm{M} \beta 2$-integrin glycoprotein. Crit Rev Immunol 2000;20:197-222.

29 Beller DI, Springer TA, Schreiber RD: AntiMac-1 selectively inhibits the mouse and human type three complement receptor. J Exp Med 1982;156:1000-1009.

-30 Stapulionis R, Oliveira CL, Gjelstrup MC Pedersen JS, Hokland ME, Hoffmann SV, Poulsen K, Jacobsen C, Vorup-Jensen T: Structural insight into the function of myelin basic protein as a ligand for integrin $\alpha \mathrm{M} \beta 2$. J Immunol 2008;180:3946-3956.

31 Dierks H, Kolanus J, Kolanus W: Actin cytoskeletal association of cytohesin-1 is regulated by specific phosphorylation of its carboxyl-terminal polybasic domain. J Biol Chem 2001;276:37472-37481.

32 Hafner M, Schmitz A, Grune I, Srivatsan SG, Paul B, Kolanus W, Quast T, Kremmer E, Bauer I, Famulok M: Inhibition of cytohesins by SecinH3 leads to hepatic insulin resistance. Nature 2006;444:941-944.

33 Karlsson A, Nixon JB, McPhail LC: Phorbol myristate acetate induces neutrophil NADPH-oxidase activity by two separate signal transduction pathways: dependent or independent of phosphatidylinositol 3-kinase. J Leukoc Biol 2000;67:396-404.

- 34 Clark SR, Ma AC, Tavener SA, McDonald B, Goodarzi Z, Kelly MM, Patel KD, Chakrabarti S, McAvoy E, Sinclair GD, Keys EM, Allen-Vercoe E, Devinney R, Doig CJ, Green FH, Kubes P: Platelet TLR4 activates neutrophil extracellular traps to ensnare bacteria in septic blood. Nat Med 2007;13: 463-469.

35 Nathan C: Points of control in inflammation. Nature 2002;420:846-852.

- 36 Theilgaard-Monch K, Jacobsen LC, Borup R, Rasmussen T, Bjerregaard MD, Nielsen FC, Cowland JB, Borregaard N: The transcriptional program of terminal granulocytic differentiation. Blood 2005; 105:1785-1796.

-37 Starr DA, Han M: ANChors away: an actin based mechanism of nuclear positioning. J Cell Sci 2003;116:211-216. 